\title{
MANAGEMENT OF GIANT INTRAGLANDULAR SUBMANDIBULAR SIALOLITH WITH NECK FISTULA
}

M.A. Almasri. Management of giant intraglandular submandibular sialolith with neck fistula. Annal Dent Univ Malaya 2005; 12: 41-45.

\begin{abstract}
Salivary gland sialolith account for the most common disease of the salivary glands. However, large calculi are considered rare. It was reported that incidence of intraglandular sialolith is rare compared to intraductal ones and may go undetected for years. In literature, few cases of submandibular giant sialolithiasis have been reported. Most of them were intraductal stones got enlarged and presented intraorally. Their management was sialolithectomy via transoral approach. However, fewer cases of large intraglandular sialolith were reported as well. Most of them led to fibrosis and erosion extended to floor of the mouth. Their management was complete surgical excision of gland and stone via extraoral extirpation approach. The present case report describes a 70 years old Saudi male patient presented with an unusual giant intraglandular submandibular sialolith with neck fistula. Orthopantomography and CT scan views were used for diagnosis. Accordingly, management was done via an extraoral incision to completely excise the gland and stone and to explorate the degree of damage and destruction at glandular and paraglandular tissues.
\end{abstract}

Key words: Giant intraglandular, submandibular sialolith, neck fistula.

\section{INTRODUCTION}

Salivary gland calculi account for the most common disease of the salivary glands (1). The exact cause of formation is unknown. However, large calculi are considered rare. It was reported that incidence of intraglandular sialolith is less common compared to intraductal ones and may go undetected for years. Findings would be incidental, unless acute phase encountered (2). Submandibular salivary glands are affected the most with sialolithiasis, followed by Parotid, sublingual, and minor glands respectively. Warthon's duct (Intraductal) lithiasis is more common to encounter than intraglandular ones. There is a slight but not significant prevalence in males. Although most cases were under the age of 40 years, sialolith may occur at any age from 6 up to 70 years old (3). The stones are formed by the precipitation of calcified structures around nucleus
Case Report

M.A. Almasri
Dept. of Oral Maxillofacial Surgery,
Faculty of Dentistry,
King Khalid University,
Asir Central Hospital,
Abha City
Saudi Arabia.
Corresponding author: Mazen A. Almasri

that is made of foreign bodies in the gland. They can be desquamated epithelial cells, degradation proteins of bacteria or the bacteria itself. Calcified structures include calcium phosphate, calcium carbonate and soluble salts present in the stone in addition to organic elements and water (4).

Zakaria (5) presented a case of a 70 years old male patient with a 20 years history of stone enlargement manifested at the floor of the mouth as fibrosis and erosion. Management was done via transoral surgical sialolithectomy. Bedner (6) presented 14 male cases with ages ranging from 25 to 61 years old. Stones mean size was $30 \times 15 \mathrm{~mm}$. He reported the use of minimally invasive transoral sialolithotomy for Warthon's ducts' stones.

The case reported by Akin and Esmer (7) showed a giant sialolith located completely inside the submandibular gland that finally led to erosion of floor of the mouth. On the other hand, Asfar et al. (8) reported three cases of giant submandibular intraglandular stones. One of them had eroded through the floor of the buccal cavity forming an orocervical fistula and pus discharge. It was preceded by swelling at the submandibular area and side of the neck. The other two cases led to fibrosis and erosion of the mouth floor. Management of all the previous intraglandular calculi was via extraoral complete surgical excision by gentle extirpation of gland and stone.

The clinical picture of frequent swelling and discharging fistula at side of the neck suggests the following differential diagnosis to be considered; Epidermoid cyst, Granulomatous diseases such TB and Sarcoid, Lipoma, Metastatic carcinoma, Salivary glands tumers (submandibular or tail of parotid gland), Cervical lymphoepithelial cyst (Branchial cyst), Cat scratch disease, Lymphoid hyperplasia (reactive lymphodenopathy) (9).

The purpose of this article is to describe the condition of a 70 years old Saudi male patient presented with an unusual giant submandibular 
sialolith associated with frequent swelling and extraoral pus discharging fistula at side of the neck that had been there for many years.

\section{CASE REPORT}

A 70 years old male patient was referred to department of oral and maxillofacial surgery at Asir Central Hospital, for management of chronic frequently pus discharging extraoral fistula. The Lesion was anterior to left sternocledomastoid muscle area three fingers below inferior mandible border. Although the patient had this problem for many years, he did not seek any medical advice since it had started.

On admission, the patient had no other known illnesses. Social history revealed heavy smoking habit for more than 30 years. All investigations (CBC, PT, APTT, Blood Chemistry, ECG, \& Chest $\mathrm{X}$-Ray) were within normal range.

The case was diagnosed using orthopantomography (OPG) and CT scan views. OPG showed round radioopaque mass about $25 \mathrm{~mm}$ in diameter just below the lower border of the mandible. An axial CT scan (Fig. 1), coronal (Fig. 2) and three dimensional (3D) simulation- reconstruction (Fig. 3) views showed about $25 \mathrm{~mm}$ in diameter, ball-shaped, well circumscribed, radioopaque mass at the area of postero-lingual aspect of the mandible body. Based on the previous diagnostic measures and the clinical examination, diagnosis was sialolith at the deep portion of submandibular salivary gland with hilus extension. This led to long term chronic inflammatory process that finally had produced the extraoral pus discharging fistula at side of the neck.

The treatment plan was complete surgical excision of submandibular salivary gland and the stone under general anesthesia. Extraoral incision was performed to expose the gland. It was fibrosed and attached firmly to the mylohyoid muscle. Extirpating the gland had revealed an extensive fibrosis and erosion of the mylohyoid muscle. After excising the gland, the stone was dissected gently off. Visual examination of the stone showed that it was ovoid in shape, firm consistency, black greenish in color surface and measured 23 x 17 mm (Fig. 4). The gland and stone were sent for histopathological examination.

The section showed salivary glands infiltrated by chronic inflammatory cells. In addition, dilated salivary duct lined by stratified squamous epithelium was observed. There was no malignancy in the sections studied. Stone chemistry analysis revealed the constituents which were positive detection of calcium, phosphate, magnesium, and ammonium.

After the surgical procedure, the patient recovery was uneventful. At one week postoperative follow up, the patient was found to be fully recovered except of mild parasthesia at side of the tongue. Follow up visits were performed at one, three and six months. It was shown that parasthesia got much better by the third visit.

\section{DISCUSSION}

It was reported that salivary gland stones may reside intraductally or within the gland substance itself (intraglandular) and may increase in size by time. This enlargement occurs due to an extra deposition of minerals, duct lining cells, debris and bacteria. The symptoms are consequence to obstruction of salivary flow. They may be presented mainly at meal time as pain and swelling distal to stone obstruction area. This usually makes the diagnosis clearer and straight forward $(10,11)$. Giant salivary gland calculi of more than $15 \mathrm{~mm}$ in diameter are

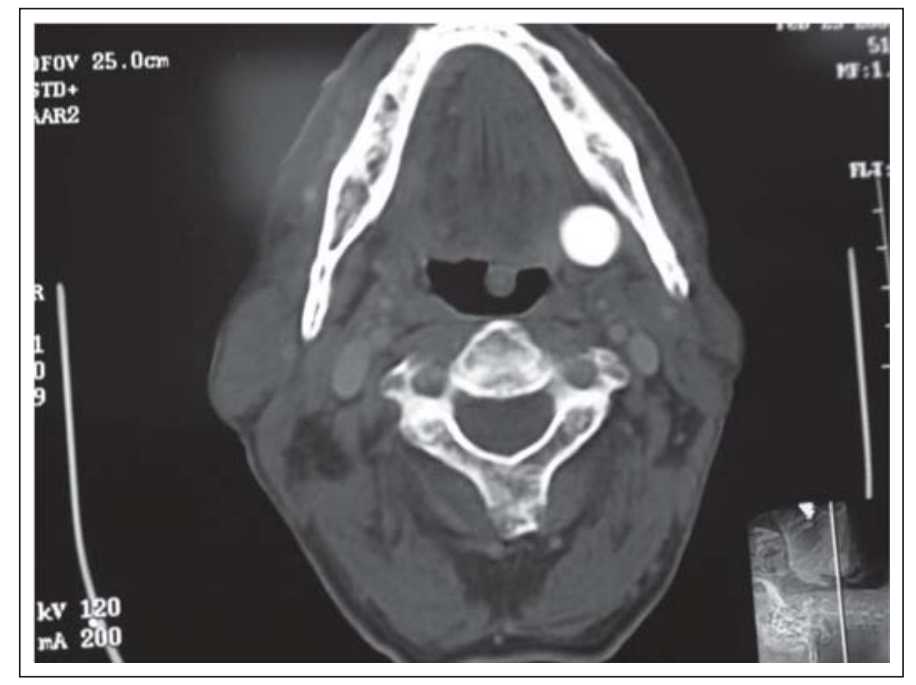

Fig. 1: Axial CT scan section showing round calcified mass medial to left mandibular ramus. 


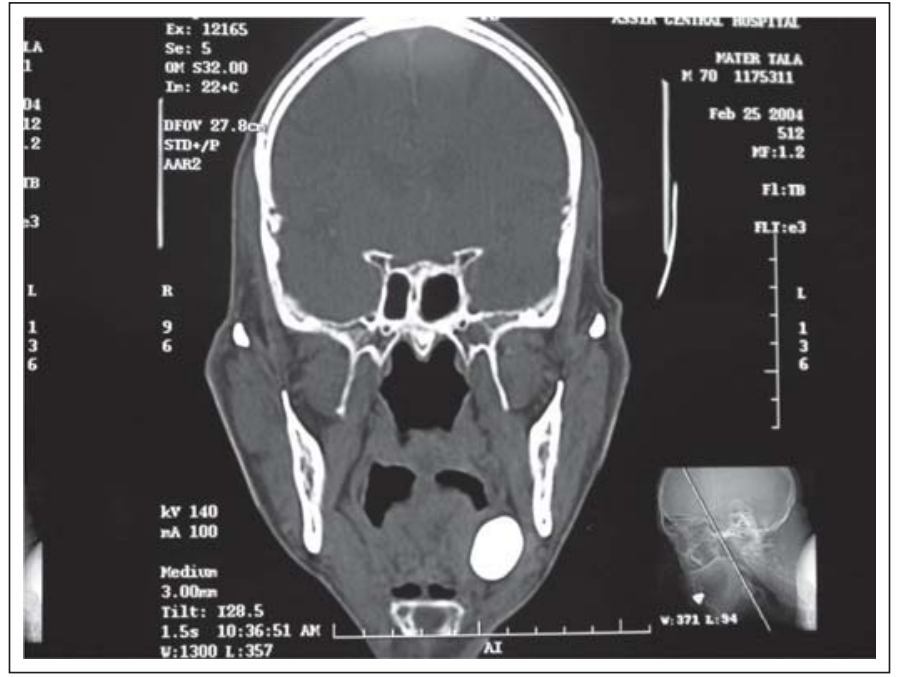

Fig. 2: Coronal CT scan section showing ovoid calcified mass medial and slightly inferior to left inferior mandible border.

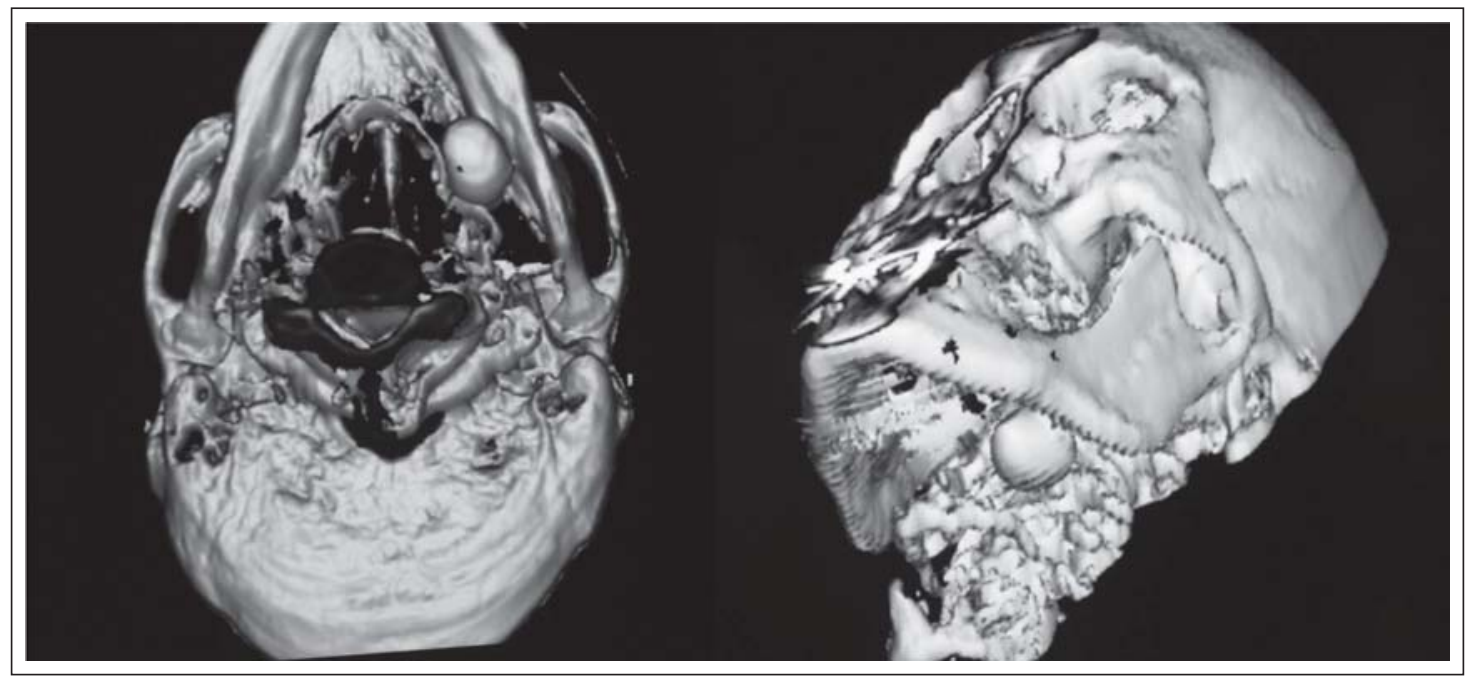

Fig. 3: Three dimensional simulation views showing the location of the submandibular sialolith from inferior and left oblique views.

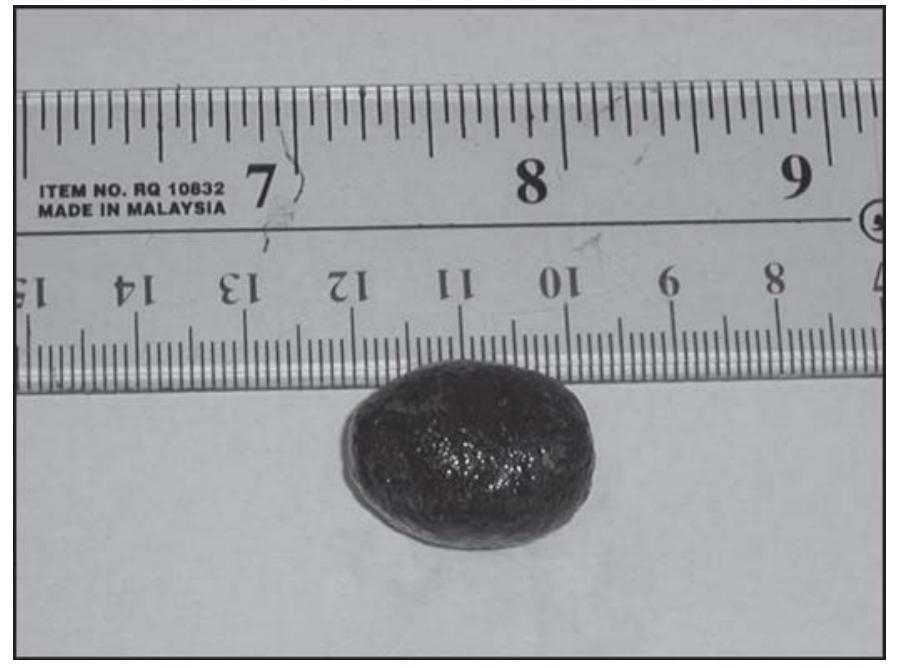

Fig. 4: Giant stone (after dissection from the submandibular salivary gland) measures approximately $23 \times 17 \mathrm{~mm}$. 
considered extremely rare (6). This might result in future perforation of the floor of the mouth (12). The degree of inflammation, atrophy and fibrosis of salivary glands are related to the duration of symptoms and the stone in-place period. The more the stone reside in-place, the more chronic manifestations may proceed (13).

The role of dentist is to diagnose such cases at an early stage. This might lead the patients to non invasive forms of treatment instead of subjecting them to invasive methods. This can be attained through the consideration of symptoms (subjective and objective) and diagnostic measures, which include history, physical examination and supplementary images (14).

Early diagnosis requires careful attention to medical history. Laforgia et al. (15) found in a clinico-epidemilogical data of 400 cases of salivary calculosis, diabetes mellitus was in $25 \%$ of cases, arterial hypertension in $20 \%$ and chronic hepatopathies in $10 \%$. Thus considering patient's systemic disorders at first visit to dental office would be of great value to early suspicion of sialolithiasis.

Supplementay diagnostic images are varied. The use of orthopantomography and ultrasound are common. Though comparison showed ultrasound is more superior (16). MR imaging has been proved to be effective in depicting wide variety of pathological changes in salivary glands. It has been shown by Sumi et al. (17) that MR imaging features may reflect chronic and acute obstruction. A combination of $\mathrm{CT}$ and MR imaging may complement each other in examining glands with sialolithiasis. High resolution CT with 3D reconstruction would be of better value (18).

During the last decade, variable techniques of diagnosis as well as treating salivary gland stones have been rapidly evolved. These are done either by surgical approaches, non surgical techniques or minimally invasive procedures $(19,20)$. Komatsuzaki et al. (18) studied the use of video-assisted submandibular sialadenectomy using ultrasonic scalpel (HS: Harmon Scalpel, Ethicon, Somerville, $\mathrm{NJ}$ ) and a special handmade lifting device to remove stones. They claimed that this technique has no complications such as marginal mandibular, hypoglossal, and lingual nerves injury, or wound haematoma formation. The amount of intraoperative bleeding by using ultrasonic scalpel ranged from 10 to $60 \mathrm{ml}$ (mean: $38.0 \mathrm{ml}$ ), while operating mean time was 232.5 minutes. Time consuming is considered the only drawback as compared to conventional extra oral surgical approaches. Otherwise video-assisted endoscopic surgery claimed to be applicable for all sialedectomy operations providing better cosmetic results.

Non surgical techniques are indicated for intraductal sialolith, anteriorly located in order to be accessible for application. The first step is toward initially pointing the location of the stone using clinical and radiographic procedures. After which, a high resolution ultrasonic probe at $7.5 \mathrm{MHz}$ is used to pinpoint the exact site where the shock waves are focused on a field of $2.5 \mathrm{~mm}$ width and $20 \mathrm{~mm}$ depth. Energy delivered is between 5 and $30 \mathrm{MPa}$. One hundred twenty impacts per minute are usual up to an average of 1500 impacts per session. One month later, a repeat session may be needed and is performed in a similar fashion. The stone residue is of a fine, sandlike consistency. The residue is evacuated by natural salivary flow or may be removed by interventional endoscopy (21).

Minimally invasive procedures indicated to diagnose and treat intraductal sialolithiasis where gland conservation is an issue. The procedure includes inrtaductal endoscopes visualization through lumen sizes of $0.4,0.8,1.0$ and $2.7 \mathrm{~mm}$. Endoscopes are present in three different types; rigid, semi rigid, and flexible. For stones of $3 \mathrm{~mm}$ or less, removal is total via grasping with forceps or endoscopic side-port suction. Larger stones need to be fragmented into smaller portions before being grasped or suctioned. If the forceps fragmentation of the stone is unsuccessful, then intracorporeal lithotripsy may break the stone. The lithotripsy energy waves are delivered through the endoscope to the surface of the stone. Pneumo-blastic, electrohydraulic, electro-magnetic, and laser-based lithotripsy energy producing machines have been used for this purpose. However, the many attempts at intracorporeal lithotripsy have shown that ductal damage and perforation are of great concern. Ductal damage will lead to eventual fibrosis and ductal stenosis. Dye lasers are the least traumatic and considered the most effective when used on yellow stones. Further details about dye laser intracorporeal lithotripsy are beyond the scope of this article. In situations where larger stones frustrate interventional endoscopic removal, a more attractive alternative to intracorporeal endoscopic lithotripsy would be extracorporeal lithotripsy. Extracorporeal lithotripsy can fragment the stone without great risk to the duct. Endoscopic removal of residual sands and fragments may then be achieved. Additionally, conventional surgery can be used if interventional endoscopes are not successful $(22,23)$.

\section{ACKNOWLEDGMENTS}

The author would like to thank Dr. Essam Elwakil, head of continuous education program at Faculty of Dentistry, King Khalid University and Dr. Bashir Saeed, chair of oral and maxillofacial surgery department at Asir Central Hospital, for their contributions to this paper and their ongoing-care to our maxillofacial patients. 


\section{REFERENCES}

1. Siddiqui SJ. Sialolithiasis: An unusually large submandibular salivary stone. Br Dent J 2002; 193: 89-91.

2. Teymoortash A, Ramaswamy A, Warner JA. Is there evidence of sphincter system in Warton's duct? Etiological factors related to sialolith formation. J Oral Sci 2003; 45: 233-5.

3. Antoniadis D, Mendonidou L, Papanayotou P, et al. Clinical study of sialolithiasis. Findings from 100 cases. Hell Stomatol Chron 1989; 33: 245-51.

4. Gunaydin Y, Karakurumer K, Ozturk A, et al. Sailolithiasis. Ankara Univ Hekim Fak Derg 1989; 16: 493-6.

5. Zakaria M. Giant calculi of submanibular salivary gland. Br J Oral Surg 1981; 19: 230-2.

6. Bodner L. Giant salivary gland calculi: diagnostic imaging and surgical management. Oral Surg, Oral Med, Oral Path, Oral Rad \& Endo 2002; 94: 320-3.

7. Akin I, Esmer N. A submandibular sialolith of unusual size. J Otolaryngol 1991; 20: 123-5.

8. Asfar SK, Steitiyeh MR, Abdul-Amir R. Giant salivary calculi: an orocervical fistula caused by a submandibular gland calculus. Can J Surg 1989; 32: 295-6.

9. Neveille WB. Differential diagnosis of oral and maxillofacial diseases. In: Neville et al, eds. Oral \& maxillofacial pathology. $1^{\text {st }}$ edn. W.B. Saunders company, 1995; 682-3.

10. Bull PD. Salivary gland stones: diagnosis and treatment. Hosp Med 2001; 62: 396-9.

11. Lozano BJ, Lopez N, Bonet M, et al. Growth rate of salivary glands calculi: an interesting case. Br J Oral Maxillofac Surg 2003; 41: 414.

12. Sutay S, Erdag K, Ikiz O, et al. Large submandibular gland calculus with perforation of the floor of the mouth. Otolaryng $\mathrm{H} \& \mathrm{~N}$ Surg 2003; 128: 587-8.
13. Harrison JD, Epivatianos A, Bhatia SN. Role of microliths in the aetiology of chronic submandibular sialadenitis: a clinicopathological investigation of 154 cases. Histopath 1997; 31: 237-51.

14. Zenk J, Constantinidis J, Kydles S, et al. Clinical and diagnostic findings of sialolithiasis. HNO 1999; 47: 963-9.

15. Laforgia PD, Favia G, Chairavalle N, et al. Clinico-statistical, morphologic and microstructural analysis of 400 cases of sailolithiasis. Minerva Stomatol 1989; 38: 1329-36.

16. Eistert B, Glanz H. Examination technique in ultrasound calculus detection in the submandibular gland. HNO 1992; 40: 144-7.

17. Sumi M, Izumi M, Yonetsu K, et al. The MR imaging assessment of submandibular gland sialoadentitis secondary to sialolithiasis: correlation with CT and histopathologic findings. AJNR 1999; 20: 1737-43.

18. Avrahami E, Englender M, Chen E, et al. CT of submandibular gland sialolithiasis. Neurorad 1996; 38: 287-90.

19. Thierbach V, Privman V, Orlian AI. Submandibular gland sialolithiasis: a case report. Gen Dent 2000; 48: 606-8.

20. Guerrissi JO, Taborda G. Endoscopic excision of the submandibular gland by an intraoral approach. J Cranifac Surg 2001; 12: 299-303.

21. Komatsuzaki Y, Ochi K, Sugiura N, et al. Video-assisted submandibular sialedenectomy using an ultrasonic scalpel. Auris Nasus Larynx 2003; 30: 75-8.

22. Katz P, Fritsch MH. Salivary stones: innovative techniques in diagnosis and treatment. Otolaryng H \& N Surg 2003; 11: 173-178.

23. Lustmann J, Regev E, Melamed Y. Sialolithiasis. A survey on 245 patients and a review of the literature. Int J Oral Maxillofac Surg 1990; 19: 135-8. 